This is a self-archived version of an original article. This version may differ from the original in pagination and typographic details.

Author(s): Minkkinen, Jaana; Auvinen, Elina; Mauno, Saija

Title: Meaningful Work Protects Teachers' Self-Rated Health under Stressors

Year: 2020

Version: Published version

Copyright: @ Authors, 2020

Rights: CC BY-NC-ND 4.0

Rights url: https://creativecommons.org/licenses/by-nc-nd/4.0/

Please cite the original version:

Minkkinen, J., Auvinen, E., \& Mauno, S. (2020). Meaningful Work Protects Teachers' Self-Rated Health under Stressors. Journal of Positive School Psychology, 4(2), 140-152.

https://doi.org/10.47602/jpsp.v4i2.209 


\title{
Meaningful Work Protects Teachers' Self-Rated Health under Stressors
}

\author{
Jaana Minkkinen', Elina Auvinen², and Saija Mauno ${ }^{1,2}$
}

\begin{abstract}
A sense of meaningfulness is one of the most sought-after work characteristics to be associated with employees' well-being. This study explored whether meaningful work enhances self-rated health in a challenging work context, under distractions, unnecessary tasks and unreasonable tasks using a holistic stress model (Nelson \& Simmons, 2003; Simmons \& Nelson, 2007) as a theoretical background. Data was collected from Finnish teachers $(N=1,658)$ and structural equation modelling was employed with the latent interaction terms. The results showed that meaningful work was associated with better self-rated health and that distractions, unnecessary tasks and unreasonable tasks were associated with poorer self-rated health. The protective potential of meaningful work against work stressors was also discovered as meaningful work mitigated the deleterious effect of unreasonable tasks on self-rated health. These findings indicate that meaningful work supports employees' self-rated health and helps them to cope better with stressful work conditions, thereby enhancing well-being. The protective quality of meaningful work means that even a challenging work context may be less harmful to employees' well-being if they have a strong sense of the meaning of their work. The practical implications of the findings for teachers and organizations are discussed.
\end{abstract}

Keywords: Meaningful work, self-rated health, distractions, unnecessary tasks, unreasonable tasks, teachers

A sense of meaningfulness is one of the most soughtafter work features and has been associated with various positive outcomes among employees (see reviews, Bailey, Yeoman, Madden, Thompson, \& Kerridge, 2018; Hu, \& Hirsh, 2017). Despite mounting empirical evidence of the importance of perceived meaningfulness at work, the connection between meaningful work and physical health seems to be an understudied issue. A link between meaningfulness, as a positive attitude towards work and physical health has been posited in the holistic stress model by Nelson and Simmons (2003; Simmons \& Nelson, 2007). Our study aims to increase knowledge about this issue and the first purpose is to explore empirically the link between meaningful work and self-rated health. We conceptualize self-rated health as a measure of physical health but also as a subcomponent of subjective well- being given that self-rated health is an individual appraisal of general health status (Bombak, 2016; Jylhä, 2009).

The second aim of this study is to explore whether meaningful work acts as a buffer against certain topical work stressors/demands, namely distractions, unnecessary tasks, and unreasonable tasks (to be defined later). Theoretically we rely on the holistic stress model (Nelson \& Simmons, 2003; Simmons \& Nelson, 2007), which offers a balanced perspective on the study of work stress, including both the positive response, eustress, and negative response, distress, and how these responses impact outcomes, e.g., physical health. As meaningfulness is seen as one indicator of eustress due to work demands (Nelson \& Simmons, 2003; Simmons \& Nelson, 2007), we assume that meaningful work could protect employees against

Corresponding Author: Jaana Minkkinen, Tampere University, Faculty of Social Sciences, ${ }^{1}$ Department of Psychology, Finland.

Email: Jaana.Minkkinen@tuni.fi

${ }^{1}$ Department of Psychology, Tampere University, Finland.

${ }^{2}$ Department of Psychology, University of Jyväskylä, Finland. 
harmful stress-related outcomes. The protective role of meaningful work against stressors has scarcely been examined (e.g., Clauss, Hoppe, Schachler, \& O'Shea, 2020) although it could be of major significance for employees' well-being in a challenging work context. To answer our research questions we study teachers, whose work is one of the most stressful occupations (e.g., Kyriacou, 2001; Conley \& You, 2009; Richards, 2012) thereby affording a relevant context to study the protective effects of meaningful work. Moreover, the teaching profession includes multiple potential features that may increase meaningfulness, such as enriching pupils' lives, which makes teachers an interesting occupational group to explore the significance of meaningful work on self-rated health.

\section{Meaningful Work and Self-Rated Health}

We define meaningful work as individuals' appraisal of their work (or of the role that work plays in their lives) having a positive meaning and significance for them (see Steger, Dik, \& Duffy, 2012; Rosso, Dekas \& Wrzesniewski, 2010). Meaningfulness at work is a positive psychological state which reflects "the extent to which one feels that work makes sense emotionally, that problems and demands are worth investing energy in, are worthy of commitment and engagement, and are challenges that are welcome" (Nelson \& Simmons, 2003; p. 106). According to the holistic stress model (Nelson \& Simmons, 2003 ; Simmons \& Nelson, 2007), meaningfulness at work is one indicator of eustress, which "reflects the extent to which cognitive appraisal of a situation or event is seen to either benefit an individual or enhance his/her well-being" (Simmons \& Nelson, 2007; p. 45). As one outcome of eustress is physical health (Nelson \& Simmons, 2003; Simmons \& Nelson, 2007), we propose that meaningful work enhances employees' self-rated health.

Empirical research has already shown that perceptions of meaningful work have positive associations with a variety of subjective measures of well-being, e.g. with happiness (Van Wingerden \& Van der Stoep, 2017), psychological well-being (Arnold, Turner, Barling, Kelloway, \& McKee, 2007; Arnold \& Walsh, 2015), work engagement (Fairlie, 2011; Johnson \& Jiang, 2016; Geldenhuys, Taba, \& Venter, 2014) and job satisfaction (Duffy, Allan, Autin, \& Bott, 2013). Recent meta-analyses have also shown that meaningful work is associated with meaningful life and overall life satisfaction (Allan, Batz-Barbarich, Sterling, \& Tay, 2019; Hu \& Hirsh, 2017), indicating that the meaningfulness in work may also have a spillover effect to other domains in life. Nevertheless, we do not yet know whether this holds for self-rated health, on which we focus here.

We conceive of self-rated health as a measure of physical health but also as a part of subjective wellbeing as it affords individuals a view of the important aspects of their health (Bombak, 2016; Zajacova \& Dowd, 2011). Research has shown that individuals understood self-rated health as a presentation of illhealth but they also linked self-rated health to their personal experiences, life situation and something which is a result of their action (Manderbacka, 1998). Thus, self-rated health is "a cross-road between the social world and psychological experiences on the one hand, and the biological world, on the other hand" (Jylhä, 2009, p. 308). Self-rated health is widely used in population health research as a measure of subjective or perceived comprehensive health (Zajacova \& Dowd, 2011) and it is a powerful and independent predictor of mortality, future health and the use of health services (Idler \& Benyamini, 1997; Jylhä, 2009). Studying teachers' self-rated health as an outcome is particularly valuable as teachers' health is important for avoiding their turnover and resignation (Schweizer \& Döbrich, 2003) and because teachers' health affects teacherstudent relationships and the quality of teaching (Kieschke \& Schaarschmidt, 2008).

\section{Meaningful Work in the Teaching Profession}

According to the theoretical framework proposed by Rosso and colleagues (2010), the sense of accomplishing meaningful work is based on individual experiences on two key dimensions: the pursuit of agency and the pursuit of communion. These desires may be oriented towards the self and others, forming four main pathways to meaningful work: individuation, contribution, self-connection and unification (Rosso et al., 2010). These pathways are discernible in the qualitative study by Willey (2016) among teachers at international schools. The study (Willey, 2016) revealed that the sense of accomplishing meaningful work is based on 1) a sense of empowerment due to professional autonomy and the joys of creativity and growth through work, referring to the sense making through individuation by Rosso et al. (2010), 2) fulfillment through making a difference in students' lives, referring to Rosso's sense making through contribution, 3) harmony through alignment of personal and professional values, referring to sense making through self-connection and 4) validity and support through meaningful relationships, referring to sense making through unification. In sum, although it is not 
within the scope of this study to explore the sources of meaningfulness, teaching as a profession can become meaningful through various psychological and social mechanisms.

As the teaching profession is one of the most demanding occupations (Kyriacou, 1987) and can provide a sense of meaningfulness in various ways, it is important to explore the connections between meaningfulness and well-being among those working in teaching. So far, the linkages between meaningful work and teachers' well-being have rarely been studied. In recent studies, meaningful work has been associated positively with work engagement among primary and secondary teachers (Ugwy \& Onyishi, 2018) and lack of meaningfulness at work has been found to be related to teachers' intentions to leave their employment in secondary schools (Janik \& Rothmann, 2015). Moreover, the study by Lavy and Bocker (2018) suggested that the positive association between teachers' sense of meaningful work and job satisfaction was mediated via better teacher-student relationships. According to the holistic stress model (Nelson \& Simmons, 2003; Simmons \& Nelson, 2007), meaningful work is seen as an indicator of eustress, which has a positive effect on physical health. We therefore posit that meaningful work has a connection with teachers' self-rated health by making a positive contribution to it.

Hypothesis $1\left(H_{l}\right)$ : Meaningful work is associated with better self-rated health among teachers.

\section{The Protective Role of Meaningful Work against Work Stressors}

Our second purpose is to study whether meaningful work can buffer against the harm of work stressors in relation to teachers' self-rated health. A vast amount of literature has claimed that the sources of teachers' stress are numerous (Boyle, Borg, Falzon, \& Baglioni, 1995; Conley \& You 2009; Geving, 2007; Kyriacou, 1987; Richards, 2012; Scheuch, Haufe, \& Seibt, 2015). Of the various work stressors teachers may encounter, we concentrate here on distractions, unnecessary tasks and unreasonable tasks. Distractions especially are a typical feature in the teaching profession (Aldrup, Klusmann, Lüdtke, Göllner, \& Trauwein, 2018), but unnecessary and unreasonable tasks have also increased in teachers' work due to organizational changes and cutbacks in schools' funding (De Simone, Cicotto, \& Lampis 2016; Richards, 2012). Including all these in the same study would provide a more comprehensive picture about which of them are most detrimental on teachers' selfrated health.
We define distractions as psychological reactions to external stimuli or competing activity which turn person's focus in a direction irrelevant to the task at hand (Jett \& George, 2003; Fletcher, Potter, \& Telford, 2018). Distractions caused, e.g., by classroom disturbances and students' problem behaviour, are typical distracting features in the teaching profession yet are fundamental part of normal working day (Aldrup et al., 2018). For example, according to a survey covering 33 countries, teachers in lower secondary education spend $13 \%$ of their lesson time keeping order in the classroom and $8 \%$ on administrative tasks (Organisation for Economic Cooperation and Development [OECD] 2014). The harmfulness of distractions in the classroom has been continuously linked with teacher burnout (see review Aloe, Shisler, Norris, Nickerson, \& Rinker, 2014) and distractions have also been related to physical symptoms and anxiety (Lin, Kain, \& Fritz, 2013). The high prevalence of distractions in teaching work and their detrimental effects on health makes it important to study whether meaningful work can protect against the harm to teachers' self-rated health due to distractions.

Unnecessary and unreasonable tasks refers to the tasks which employees are obliged to accomplish besides their core tasks, but which they perceive as something they should not be expected to do (Semmer et al., 2015). Unnecessary tasks are tasks that would not exist if the work or the tasks had been organized differently. For example, unnecessary tasks in the teaching profession are administrative tasks not necessary for achieving the teaching goals or tasks occurring as a result of ineffective technological or organizational systems (Semmer et al., 2015). Unreasonable tasks refers to tasks that do not originally belong to the teacher's professional role, in other words, someone else should do them (Semmer et al., 2015). This results in a mismatch between teachers' beliefs about core tasks and e.g., institutional demands of arranging the job. Unnecessary and unreasonable tasks are work stressors/demands which so far have been little studied, particularly among teachers. The empirical research so far has shown that unnecessary and unreasonable tasks predict strain, irritability, feelings of resentment towards home organization and poorer job performance (Ma \& Peng, 2019; Semmer et al., 2015). Thus, more research evidence is needed, particularly from the viewpoint of meaningful work as a buffer against their adverse effects on self-rated health.

To sum up, distractions, unnecessary tasks and unreasonable tasks may harm employees' subjective 
well-being indicating their adverse impact through distress (Nelson \& Simmons, 2003; Simmons \& Nelson, 2007). Among teachers, all three work stressors/demands may act likewise, preventing teachers from focusing on their core task, i.e., teaching, and this may cause the negative stress response, distress, which is likely to result in impairments to physical health (Nelson \& Simmons, 2003; Simmons \& Nelson, 2007). Overall, the connection between distress and physical health has been explained by the disturbance of the natural balance due to the sustained stress response, which may cause ill-health and diseases through prolonged neurophysiological activation and pathophysiological processes (see e.g., Ursin \& Eriksen, 2004). Also, empirical research has shown that work stressors predict various physical symptoms (Nixon, Mazzola, Bauer, Krueger, \& Spector, 2011). We therefore assume that distractions, unnecessary tasks and unreasonable tasks may impair teachers' selfrated health.

Hypothesis $2\left(\mathrm{H}_{2}\right)$ : Distractions, unnecessary tasks and unreasonable tasks are associated with poorer selfrated health among teachers.

However, stressors/demands at work do not necessarily lead to the negative outcomes and stress is not necessarily something to be avoided (Selye, 1976). The same stressors/demands can be assessed as threatening, leading to distress, or as non-threatening, leading to eustress (Nelson \& Simmons, 2003; Simmons \& Nelson, 2007) depending on how individuals interpret them as the cognitive appraisal approach has highlighted (Lazarus, DeLongis, Folkman, \& Gruen, 1985). According to the holistic stress model (Nelson \& Simmons, 2003; Simmons \& Nelson, 2007), the same stressors/demands may simultaneously elicit both positive responses and negative responses and these interact with each other (Simmons \& Nelson, 2007; p. 44). Consequently, we assume that perceived work meaningfulness, as an indicator of positive response, interacts with the common stressors of the teaching occupation (i.e., distractions, unnecessary tasks and unreasonable tasks) and may protect self-rated health against the adverse effects of these work stressors/demands.

Hypothesis $3\left(\mathrm{H}_{3}\right)$ : Meaningful work mitigates the association between work stressors - distractions, unnecessary tasks and unreasonable tasks - and poorer self-rated health.

\section{Method}

\section{Procedure and Participants}

This study is part of a larger research project (Managing new intensified job demands through selfregulative resources: A large-scale study across occupations and age groups, IJDFIN) examining mental work demands and employee well-being in different occupational groups, including teachers. Participation in a survey was voluntary and all participants were adults. The survey was completed online, optimized for both computers and mobile devices and tested separately before data collection. Data was anonymized as a part of the ethical procedure.

A total of 2,434 currently working members on the register of the Trade Union of Education (OAJ) participated in the study in spring 2018. The participants were recruited via the trade union as of all Finnish teachers $95 \%$ belonged to a trade union in 2015 (OAJ, 2015). Random sampling included 5,076 individuals and the response rate was $48 \%$. More women $(79 \%)$ participated in the study, but the gender difference was not statistically significant compared to trade union membership. For the OAJ, the data consists of more people from the two oldest age groups (51-60 years and 61+ years) than the OAJ membership.

Questions about distractions were posed to 2,185 respondents who participated in the main survey after the pilot survey. After excluding respondents whose main job was not teaching (e.g., work in office or administrative tasks) the final sample consisted of those 1,658 teachers who had reported their self-rated health. The meaningful work items yielded responses from 1,623-1,628 teachers, and the corresponding figures were $1,652-1,655$ for distraction items, $1,650-1,657$ for unnecessary tasks, 1,648-1,653 for unreasonable tasks, 1,654 for gender and 1,656 for age. Gender and age were included in the analyses as sociodemographic control variables as they have been shown to be linked to teachers' self-rated health (Schweizer \& Döbrich, 2003). Of the respondents, $80.1 \%$ were women, their ages varied from 24 to 68 years $(M=49.1, S D=10.8)$. A total of $11.1 \%$ worked in supervisory positions and $81.0 \%$ had a permanent employment contract. In the final sample, $92.2 \%$ reported their main field of education and of these participants, $16.4 \%$ worked in pre-primary education (for children up to 7-years-old), $41.7 \%$ in comprehensive schools (for 7-16-years-olds), $14.8 \%$ in upper secondary schools (for 16-18-yearsolds), $13.4 \%$ in vocational institutions, $4.6 \%$ in universities of applied sciences, $2.4 \%$ in folk high school, $2.2 \%$ in universities, $1.7 \%$ in adult education centers, $1.4 \%$ in art schools for children and adolescents 
and $1.4 \%$ in other educational institutions. The level of education was high among the respondents: $3.3 \%$ had university postgraduate degrees (PhD), 68.9\% a master's degree from a university, and $20.4 \%$ had a master's degree from a university of applied sciences or a bachelor's degree from a university.

\section{Measures}

Self-rated health was measured with a single item, which is a commonly used procedure in the field in population health studies (Jylhä, 2009; Zajacova \& Dowd, 2011): "In general, would you say your health is poor, fair, good, very good, or excellent?" (scale 1$5 ; M=3.22, S D=0.97$, skewness $=.036$, kurtosis $=$ $.530)$. The predictive validity of a one-item question of self-rated health is high as measured by its association with mortality, morbidity, disability and use of health services (Jylhä, 2009; Zajacova \& Dowd, 2011). Of the teachers studied, $76.4 \%$ reported that their health was good, very good, or excellent.

Meaningful work was measured using The Work and Meaning Inventory (Steger et al., 2012) and its subscale of positive meaning, which measures whether individuals experience meaningfulness in relation to their work. The subscale of positive meaning was used as it is deemed the most fundamental indicator of overall work meaningfulness and best captures how employees assess how their work matters in their lives (Steger et al., 2012). It fitted theoretically best as an indicator of eustress in the holistic stress model (Nelson \& Simmons, 2003; Simmons \& Nelson, 2007) as it is focused on the positive aspects of work in the lives of employees. The sub-scale includes four items ("I have found a meaningful career", "I understand how my work contributes to my life's meaning", "I have a good sense of what makes my job meaningful", "I have discovered work that has a satisfying purpose"). All items were rated on a seven-point Likert-scale $(1=$ do not agree at all, $7=$ totally agree), higher scores reflecting more meaningful work $(M=5.86, S D=.96)$. Cronbach's alpha coefficient $(\alpha)$ was .88. Of the participating teachers, $74.2 \%$ agreed or totally agreed that they had (positive) meaningful work.

Distractions were assessed using five distraction items from the Interruption Scale developed by Fletcher and colleagues (2017; e.g., "It was hard to keep my attention on my work because of distractions in my workplace", "A noise or other distraction interrupted my workflow".) The items were rated with a six-point Likert-scale ( $1=$ never, $6=$ very frequently), higher scores reflecting more distractions $(M=3.50, S D=$
$1.05, \alpha=.86)$. A total of $16.1 \%$ of teachers reported distractions often or very often, $35.3 \%$ sometimes.

Unnecessary and unreasonable tasks were assessed using eight items from the Bern Illegitimate Tasks Scale (Semmer, Tschan, Meier, Facchin, \& Jacobshagen, 2010). Unnecessary tasks were measured with four items (e.g., "Do you have work tasks to take care of which keep you wondering if they have to be done at all?") and unreasonable tasks with four items (e.g., "Do you have work tasks to take care of which you believe should be done by someone else?"). Answers were given on a five-point Likert-scale $(1=$ never, $5=$ often $)$. Cronbach's alpha was .87 for unnecessary tasks $(M=$ $3.18, S D=.85)$ and .89 for unreasonable tasks $(M=$ $2.89, S D=.87)$. Of the teachers, $38.2 \%$ reported that they had unnecessary tasks quite often or often, while $25.3 \%$ of teachers reported having unreasonable tasks quite often or often.

Control variables gender and age were included in the analyses as earlier research has shown that male and older teachers report lower levels of self-rated health (Schweizer \& Döbrich, 2003). Respondents reported their gender (coded as female $=0$, male $=1$ ) and age (in years, used as continuous variable).

\section{Analysis}

Confirmatory factor analyses (CFA) were run first to ascertain whether the latent variables in the analyses were separate constructs. Secondly, correlations between the latent factors and control variables were explored. Thirdly, structural equation models (SEMs) were executed to examine the hypothesized paths in self-rated health using maximum likelihood robust estimation. Models $1 \mathrm{a}$ and $1 \mathrm{~b}$ included direct effects. Model 2 also included two latent interaction products (meaningful work $\times$ distractions, meaningful work $\times$ unreasonable tasks). Unnecessary tasks were dropped from Model 2 due to their not being significantly associated with self-rated health in Model 1b. Gender and age were used as control variables in all models. Lastly, one significant interaction found in Model 2 was plotted in the figure for closer scrutiny.

The fit for the CFA and SEM models without an interaction product was assessed using Chi-square values $\left(\chi^{2}\right)$, comparative fit index (CFI), Tucker-Lewis index (TLI), root mean square error of approximation (RMSEA) and standardized root mean square residual (SRMR). The cutoff values were .95 for CFI and TLI, .06 for RMSEA and .08 for SRMR (Hu \& Bentler, 1999; Marsh, Hau, \& Wen, 2004). As the abovementioned fit indices are not available for SEM with the latent interaction product (Model 2), a two-step 
method was utilized to evaluate the model fit (Maslowsky, Jager, \& Hemken, 2015; Muthén \& Muthén, 1998-2017, pp. 78-79). The fit was considered good if the model without the latent interaction term fitted well according to the abovementioned fit indices and the log-likelihood ratio test was not significant comparing models with the latent interaction term and without it. Moreover, the local effect size of the interaction effect was estimated with the proportion reduction in variance (PRV; Peugh, 2010) of self-rated health comparing the model with the latent interaction term and without it. The full information maximum likelihood procedure (FIML; see Muthén \& Muthén, 1998-2017) was applied for handling a few missing values with Mplus statistical package (version 8.4). The missing data percentages in the study variables varied $0-2.1 \%$.

\section{Results}

\section{Preliminary Analysis}

Measurement models via CFA with 1-4 factors showed that meaningful work, distractions, unnecessary tasks and unreasonable tasks were separate constructs in the sample as the model with four factors had the best fit $\left(\chi^{2}(113)=945.942, p<.001 ; \mathrm{CFI}=.949 ; \mathrm{TLI}=.938 ;\right.$ RMSEA $=.067 ;$ SRMR $=.034)$ and fitted the data significantly better than the model with three factors (unnecessary and unreasonable tasks as one single factor) according to chi-square difference $(\mathrm{p}<.001)$ and other fit indices. The fit was very poor for one- and twofactor CFAs (the fit indices for CFAs with 1-3 factors are available from the authors upon request). In the CFA including four factors, all standardized factor loadings were significant at the .001 level, ranging from .74 to .92 . Table 1 shows the correlations between the latent factors and control variables.

\section{The Relationship between Meaningful Work and Self-Rated Health}

Meaningful work was significantly associated with better self-rated health according to the standardized beta coefficient $\left(b^{*}=.30, p<0.001\right.$, Model 1a, Table 2 ). This link also held when distractions, unnecessary tasks and unreasonable tasks were included in the analysis $\left(b^{*}=.23, p<0.001\right.$, Model $1 \mathrm{~b}$, Table 2$)$. These results provided support for $\mathrm{H} 1$, indicating that meaningful work also contributed to better self-rated health when work stressors and control variables were included in analysis.

In turn, more frequent distractions and unreasonable tasks were associated with poorer self-rated health (respectively, $b^{*}=-.16, p<.001 ; b^{*}=-.09, p<.05$; Models $1 \mathrm{~b}$; Table 2) thereby supporting H2. However, unnecessary tasks were not significantly related to poorer self-rated health $\left(b^{*}=-.00, n s\right)$ although the correlation between them was significant $(r=-.23, p<$ .001 ; Table 1). One explanation for this is that distractions, unnecessary tasks and unreasonable tasks correlated with each other (see Table 1) and explained the same shared variance of self-rated health. The strongest correlation was between unnecessary tasks and unreasonable tasks $(r=.71, p<.001)$, and of these, only unreasonable tasks were associated with self-rated health when both were in the same analysis (Model 1b). Hence, unnecessary tasks were not included in Model 2. Both control variables, gender and age, had significant associations with self-rated health, which was reportedly better among men than among women and among younger than among older respondents (see Table 2). The model fit was good (respectively, $\chi^{2}(152)$ $=1091.53, p<.001 ; \mathrm{CFI}=.94 ; \mathrm{TLI}=.93 ; \mathrm{RMSEA}=$ $.06 ; \mathrm{SRMR}=.03)$.

Table I. Summary of intercorrelations, means and standard deviations for the analysis variables

\begin{tabular}{|c|c|c|c|c|c|c|c|}
\hline Measure & 1 & 2 & 3 & 4 & 5 & 6 & 7 \\
\hline 1. Self-rated health & - & & & & & & \\
\hline 2. Meaningful work & $.28 * * *$ & - & & & & & \\
\hline 3. Distractions & $-.28 * * *$ & $-.26 * * *$ & - & & & & \\
\hline 4. Unnecessary tasks & $-.23 * * *$ & $-.33 * * *$ & $.51 * * *$ & - & & & \\
\hline 5. Unreasonable tasks & $-.24 * * *$ & $-.25 * * *$ & $.54 * * *$ & $.71 * * *$ & - & & \\
\hline 6. Gender & $.08^{* *}$ & $-.10 * * *$ & $-.13 * * *$ & $.06^{*}$ & $-.06^{*}$ & - & \\
\hline 7. Age & $-.09 * * *$ & .02 & .05 & $.09 * *$ & .05 & -.00 & - \\
\hline$M$ & 3.22 & 5.86 & 3.50 & 3.18 & 2.89 & 0.20 & 49.11 \\
\hline$S D$ & .97 & .96 & 1.05 & .85 & .87 & .40 & 10.8 \\
\hline Range & $1-5$ & $1-7$ & $1-6$ & $1-5$ & $1-5$ & $0 / 1$ & $24-68$ \\
\hline Cronbach's alpha & - & .88 & .86 & .87 & .89 & - & - \\
\hline
\end{tabular}

Note. Means, standard deviations and range based on mean variables. Correlations based on latent factors (variables 2-5) and measured self-rated health and control variables. Gender: $0=$ female, $1=$ male. ${ }^{*} p<.05, * * p<.01, * * * p<.001$, two-tailed. 
Table 2. Meaningful work explaining the variance in self-rated health

\begin{tabular}{|c|c|c|c|c|c|c|}
\hline \multirow[b]{2}{*}{ Predictor } & \multicolumn{2}{|c|}{ Model 1a } & \multicolumn{2}{|c|}{ Model 1b } & \multicolumn{2}{|c|}{ Model 2} \\
\hline & $b^{*}$ & $S E$ & $b^{*}$ & $S E$ & $b^{*}$ & $S E$ \\
\hline Meaningful work & $.30 * * *$ & .02 & $.23 * * *$ & .03 & $.26 * * *$ & .03 \\
\hline Distractions & & & $-.16^{* * *}$ & .03 & $-.13 * * *$ & .03 \\
\hline Unnecessary tasks & & & -.00 & .04 & & \\
\hline Unreasonable tasks & & & $-.09 *$ & .04 & $-.12 * * *$ & .03 \\
\hline Gender & $.11 * * *$ & .02 & $.08 * *$ & .02 & $.08 * * *$ & .02 \\
\hline Age & $-.09 * * *$ & .02 & $-.08 * *$ & .02 & $-.08 * *$ & .02 \\
\hline Meaningful work $\times$ Distractions & & & & & .01 & .04 \\
\hline Meaningful work $\times$ Unreasonable tasks & \multirow{2}{*}{\multicolumn{2}{|c|}{$.98 / .96$}} & & & $-.10 *$ & .04 \\
\hline CFI/TLI & & & \multicolumn{2}{|c|}{$.94 / .93$} & \multicolumn{2}{|c|}{ a } \\
\hline RMSEA & \multicolumn{2}{|c|}{.07} & \multicolumn{2}{|c|}{.06} & \multicolumn{2}{|c|}{ a } \\
\hline SRMR & \multirow{2}{*}{\multicolumn{2}{|c|}{$\begin{array}{l}.02 \\
100\end{array}$}} & \multicolumn{2}{|c|}{.03} & \multicolumn{2}{|c|}{ a } \\
\hline$R^{2}$ & & & \multicolumn{2}{|c|}{.145} & \multicolumn{2}{|c|}{.168} \\
\hline
\end{tabular}

Note. $b^{*}=$ standardized regression coefficient, $S E=$ standard error. ${ }^{a}$ unavailable for the model with the latent interaction product of continuous latent variables.

$* p<.05, * * p<.01, * * * p<.001$, two-tailed.

\section{The Interaction of Meaningful Work and Work Stressors}

We ran SEM including two latent interaction terms (Model 2) to test whether distractions and unreasonable tasks interacted with meaningful work in relation to self-rated health. The results showed that meaningful work moderated the association between unreasonable tasks and self-rated health $\left(b^{*}=-.10 ; p<.05\right.$; Table 2$)$. This finding partly supported $\mathrm{H} 3$, indicating that meaningful work acted as a protective buffer against the harmful effect of unreasonable tasks on self-rated health. Instead, the interaction between meaningful work and distractions was not significant in Model 2, thus not supporting $\mathrm{H} 3$. The model explained $16.8 \%$ of the variance in self-rated health. According to the local effect size (PRV), the interaction term explained an additional $1 \%$ of the variance in self-rated health. The model fit was acceptable for the interaction model as the fit was acceptable for the model without interaction terms and the log-likelihood ratio test was not significant $(p=.993)$ when comparing models with and without the interaction terms.

We plotted the significant interaction between meaningful work and unreasonable tasks on self-rated health to explore it more closely. We were especially interested to see whether meaningful work had a buffering effect when the level of unreasonable tasks was high (one standard deviation above the mean), that is, when teachers reported unreasonable tasks quite often in their work (see the solid line in Figure 1). As can be seen in Figure 1, self-rated health was better among teachers who totally agreed that their work was meaningful (1 $S D$ above the mean) than among those who reported that they found their work meaningful only to some extent (1SD below the mean) when both groups reported unreasonable tasks quite often in their work. Thus, meaningful work also had a buffering effect when the level of unreasonable tasks was high. Furthermore, the greater the meaningfulness perceived at work, the better the self-rated health when the level of unreasonable tasks was low (1 SD below the mean; see dashed line in Figure 1).

\section{Discussion}

This study increased the knowledge about the importance of meaningful work by pointing out its positive contribution to employees' self-rated health. Based on the large and representative data from Finland, the results showed that teachers experiencing more meaningfulness in their work reported better selfrated health than did those who found their work less meaningful. Even more importantly, this positive link remained in the challenging work context, under the stressors of distractions, unnecessary tasks and unreasonable tasks, of which distractions in particular are common stressors in teachers' work (Aldrup et al., 2018; OECD, 2014). In addition, the protective effect of meaningful work against one work stressor, unreasonable tasks, was identified. This finding increases the understanding of the indirect connections between meaningful work and self-rated health. 


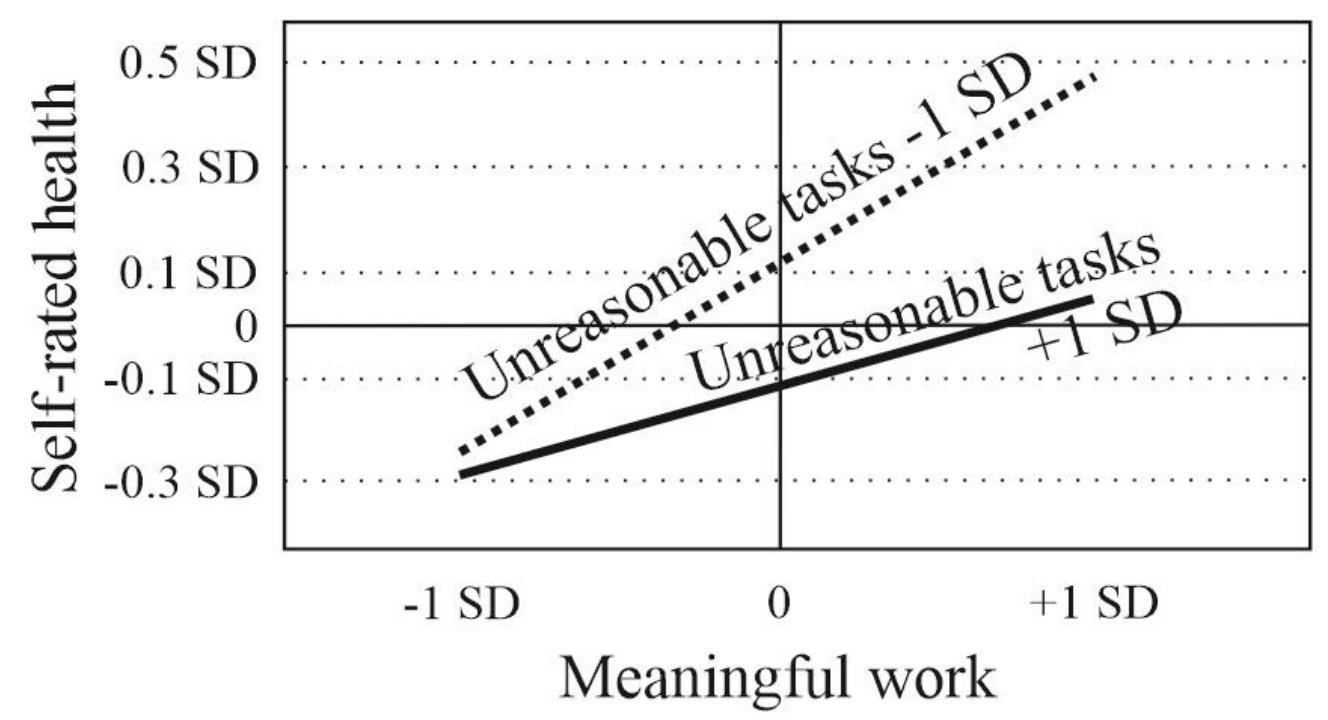

Figure I. The interaction effect of unreasonable tasks and meaningful work on self-rated health. Note: The figure includes standardized estimates. $S D=$ standard deviation

The main finding in this study, the positive link between meaningful work and self-rated health, has been very little studied. This finding was anticipated, as the holistic stress model has argued that perceived meaningfulness of work is one indicator of eustress, which predicts better physical health (Nelson \& Simmons, 2003; Simmons \& Nelson, 2007). Our finding also corroborates the findings of a great deal of earlier research on the significance of meaningful work for employees' well-being (Van Wingerden \& Van der Stoep, 2017; Arnold et al., 2007; Arnold \& Walsh, 2015; Fairlie, 2011; Johnson \& Jiang, 2016; Geldenhuys et al., 2014; Ugwy \& Onyishi, 2018; Duffy et al., 2013; Lavy \& Bocker, 2018). Yet one might ask why meaningful work is associated with better selfrated health. We suggest that the presence of positive or pleasurable psychological states and attitudes, like meaningfulness at work (Nelson \& Simmons, 2003; Simmons \& Nelson, 2007) may help to maintain the natural neurophysiological balance, i.e., preventing prolonged neurophysiological activation and blocking pathophysiological processes and diseases, which further supports self-rated health. This proposal is in analogy with the widely acknowledged and tested physiological explanation for the connection between distress and physical ill-health (see e.g., Ursin \& Eriksen, 2004). This hypothetical connection between perceived meaningfulness at work and natural neurophysiological balance needs to be further studied with adequate study designs. Moreover, the connection between meaningful work and self-rated health could be mediated via job satisfaction and life satisfaction (see Allan et al., 2019), of which job satisfaction has been shown to be associated with physical illnesses
(Faragher et al., 2005) and life satisfaction with selfrated health (Kööts-Ausmees \& Realo, 2015).

Our second key finding was that meaningful work diminished the adverse association between unreasonable tasks and self-rated health. This finding is consistent with a recent study where meaningful work mitigated the harm of workload on occupational health (Clauss et al., 2020). Although in our study the protective effect was small in size, it nevertheless suggests that a challenging work context may entail less harm to employees' well-being when they have a strong sense of meaning at work. Using the cognitive appraisal approach (Lazarus et al., 1985), this finding could be explained in such a way that meaningfulness at work affects the perception of work stressors and ability to cope through its cognitive assessment and interpretation (Nelson \& Simmons, 2003; Simmons \& Nelson, 2007). In other words, teachers who perceived their work to be extremely meaningful, did not necessarily assess unreasonable tasks as such severe stressors, which decreased the stress response and helped teachers to cope better with unreasonable tasks as a consequence. This finding also suggests that eustress (indicated in this study by meaningful work) can change the effect of the negative stress response, distress, on self-rated health (see Brulé \& Morgan, 2018; Nelson \& Simmons, 2003; Simmons \& Nelson, 2007).

Contrary to our expectations, we found no buffering effects of meaningful work against distractions or unnecessary tasks. It is possible that distractions in the teaching profession are so overwhelming (Aldrup et al., 2018) that the only way to affect their adverse link with self-rated health may be to decrease the number of 
distractions itself. Of the work demands explored in this study, distractions showed the strongest adverse association with self-rated health, which is a connection that has not been described before in any published studies. However, this result supports previous findings on the relationships between distractions and teachers' physical symptoms and burnout (Lin et al., 2013; Aloe et al., 2014). Also, our finding regarding the link between unreasonable tasks and poorer self-rated health is consistent with the findings of earlier studies, showing the deleterious effect of unreasonable tasks on employees' well-being (Semmer et al., 2015). In contrast to these studies and our hypothesis, unnecessary tasks were not related to self-rated health in this study. This suggests that unnecessary tasks may not be such severe work stressors among teachers, at least regarding self-rated health, when distractions and unreasonable tasks are taken into account. In future, more research is needed in the interaction between meaningful work and other work stressors so as to learn more about the protective role of meaningful work in variously demanding occupational settings.

Taken together, our results show the relevance of meaningful work for self-rated health. As noted in the introduction, the relationship between self-rated health and actual physiological health is not entirely straightforward. However, on the population level, selfrated health is indisputably a valid measure of physical health as it has been shown to be consistent with objective health status correlating with the prevalence of many diseases (e.g., Wu et al., 2013). Moreover, physical health and chronic diseases predict self-rated health (Bailis, Segall, \& Chipperfield, 2003; Leinonen, Heikkinen, \& Jylhä, 2001) and poor self-rated health predicts mortality better than any objective measure (Jylhä, 2009). From this point of view, our results highlight that meaningful work is of relevance for teachers' actual physiological health, which in turn, is important for the quality of teaching and teacher-pupil relationships (Kieschke \& Schaarschmidt, 2008). Although meaningful work is only one factor among many contributing to individual's health, it may have far-reaching significance in people's lives, e.g., for a longer working career, as good health decreases staff turnover and resignations (Schweizer \& Döbrich, 2003). The linkage between meaningful work and health remains to be discussed, as staying in a workplace which does not fulfill individuals' desires for purposeful work is not only uncomfortable or unmotivating on a daily basis, but may also have subsequent implications for physical health.
On the other hand, self-rated health is a subjective assessment and reflects subjective well-being as each individual decides which features to take into consideration when evaluating self-rated health (Bombak, 2016; Jylhä, 2009). Moreover, an evaluation of own health status depends on culturally and historically varying concepts of health, reference groups, earlier health experiences, health expectations, positive or negative disposition and cultural conventions in expressing positive and negative opinions (Jylhä, 2009). Therefore, future research should also focus on objective measures of health when exploring the role of meaningful work in employees' health.

\section{Limitations and Practical Implications}

The strengths of this study are a high response rate, representativeness of data compared to the Finnish teacher population and the use of validated scales. As a limitation, the results are limited to teachers and more research is needed to confirm the findings in other professional groups. Due to the cross-sectional design, drawing conclusions regarding causality is not possible and therefore longitudinal designs are needed to verify our findings. It should also be noted that shared method variance may to a certain extent have effects on the associations found as the study is based on self-reports only. Moreover, controlling for measurement error with a one-item indicator of self-rated health was not possible. In future, other than one-item indicators could be used as well, however; it is standard procedure to assess self-rated health with only one item (Jylhä, 2009; Zajacova \& Dowd, 2011). Finally, only the sub-scale of positive meaning was used in this study (Steger et al., 2012).

As the results showed that meaningful work supports employees' self-rated health, it is recommended already to pay attention to those aspects which increase the sense of meaning at work at the early stage of career choice. Moreover, this study suggests that employees' self-rated health can be promoted by improving those job characteristics which enhance meaningfulness at work. In the teaching profession, this could include job crafting (see e.g., Petrou, Demerouti, Peeters, Schaufeli, \& Hetland, 2012; Tims, Bakker, \& Derks, 2013) but the school community can also support teachers' perceptions of meaningful work by imparting a sense of belongingness and shared values (Rosso et al., 2010). The recent research suggests that contextual level factors are just as important as individual level factors in promoting teachers' coping (Ainsworth \& Oldfield, 2019). For example, school 
principals can offer opportunities for professional development, which supports teacher's sense of meaningful work by enhancing self-efficacy and selfesteem (Rosso et al., 2010). As new situations induce more stress (Ursin \& Eriksen, 2004), continuous training is needed to help teachers to cope better with new challenges in their work, e.g., organizational changes, cutbacks in resources in schools, and increasing investments in technological innovations in teaching methods (De Simone, Cicotto, \& Lampis 2016; Richards, 2012). Teachers' autonomy should also be conserved as coping with stress is easier in situations that are under personal control (Spector, 1998). At the organizational level, more attention should be paid to limiting distractions and unreasonable tasks in teachers' work to minimize the toll they take on teachers' health. Also, planning school buildings conducive to working conditions that allow teachers to work without distractions from outside the classroom or other teaching facilities is called for.

\section{Compliance with Ethical Standards}

\section{Ethical Approval}

All authors contributed to the study conception and design. Material preparation, data collection and analysis were performed by Jaana Minkkinen and Elina Auvinen. The first draft of the manuscript was written by Jaana Minkkinen and all authors commented on previous versions of the manuscript. All authors read and approved the final manuscript.

\section{Declaration of Conflicting Interests}

The authors declared no potential conflicts of interest with respect to the research, authorship, and/or publication of this article.

\section{Funding}

This research was funded by Academy of Finland (grant number 308334).

\section{ORCID}

Jaana Minkkinen(i) https://orcid.org/0000-0002-94579599

\section{References}

Ainsworth, S., \& Oldfield, J. (2019). Quantifying teacher resilience: Context matters. Teaching and Teacher Education, 82, 117-128.

Aldrup, K., Klusmann, U., Lüdtke, O., Göllner, R., \& Trauwein, U. (2018). Student misbehavior and teacher well-being: Testing the mediating role of the teacher-student relationship. Learning and Instruction, 58, 126-136.

Allan, B. A., Batz-Barbarich, C., Sterling, H. M., \& Tay, L. (2019). Outcomes of meaningful work: A meta-analysis. Journal of Management Studies, 56(3), 500-528.

Aloe, A. M., Shisler, S. M., Norris, B. D., Nickerson, A. B., \& Rinker, T. W. (2014). A multivariate meta-analysis of student misbehavior and teacher burnout. Educational Research Review, 12, 30-44.

Arnold, K. A., Turner, N., Barling, J., Kelloway, E. K., \& McKee, M. C. (2007). Transformational leadership and psychological well-being: The mediating role of meaningful work. Journal of Occupational Health Psychology, 12(3), 193-203.

Arnold, K. A., \& Walsh, M. M. (2015). Customer incivility and employee well-being: Testing the moderating effects of meaning, perspective taking and transformational leadership. Work and Stress, 29, 362-378.

Bailey, C., Yeoman, R., Madden, A., Thompson, M., \& Kerridge, G. (2018). A review of the empirical literature on meaningful work: Progress and research agenda. Human Resource Development Review, 18(1), 83-113.

Bailis, D. S., Segall, A., \& Chipperfield, J. G. (2003). Two views of self-rated general health status. Social Science \& Medicine, 56, 203-217.

Bombak, A. E. (2013). Self-rated health and public health: A critical perspective. Frontiers in Public Health, 1, 15.

Boyle, G. J., Borg, M. G., Falzon, J. M., \& Baglioni, A. J. Jr. (1995). A structural model of the dimensions of teacher stress. British Journal of Educational Psychology, 65(1), 49-67.

Brulé, G., \& Morgan, R. (2018). Working with stress: Can we turn distress into eustress? Journal of Neuropsychology \& Stress Management, 3, 1-3.

Received: February 10, 2020 Accepted: June 19, 2020 Published Online: July 3, 2020
Clauss, E., Hoppe, A., Schachler, V., \& O'Shea, D. (2020). Occupational self-efficacy and work engagement as moderators in the stressordetachment model. Work \& Stress. https://doi.org/10.1080/02678373.2020.1743790 
Conley, S., \& You, S. (2009). Teacher role stress, satisfaction, commitment, and intentions to leave: A structural model. Psychological Reports, 105(3), 771-786.

De Simone, S., Cicotto, G., \& Lampis, J. (2016). Occupational stress, job satisfaction and physical health in teachers. Revue européenne de psychologie appliquée, 66, 65-77.

Duffy, R. D., Allan, B. A., Autin, K. L., \& Bott, E. M. (2013). Calling and life satisfaction: It's not about having it, it's about living it. Journal of Counseling Psychology, 60, 42-52.

Fairlie, P. (2011). Meaningful work, employee engagement, and other key outcomes: Implications for human resource development. Advances in Human Resources, 13, 508-525.

Faragher, E. B., Cass, M., \& Cooper, C. L. (2005). The relationship between job satisfaction and health: A meta-analysis. Occupational and Environmental Medicine, 62, 105-112.

Fletcher, K. A., Potter, S. M., \& Telford, B. N. (2018). Stress outcomes of four types of perceived interruptions. Human Factors, 60(2), 222-235.

Geldenhuys, M., Laba, K., \& Venter, C. M. (2014). Meaningful work, work engagement and organizational commitment. SA Journal of Industrial Psychology, 40(1), Art. \#1098.

Geving, A. M. (2007). Identifying the types of student and teacher behaviours associated with teacher stress. Teaching and Teacher Education, 23(5), 624-640.

Hu, J., \& Hirsh, J. (2017). The benefits of meaningful work: A meta-analysis. Academy of Management Annual Meeting Proceedings, 1. Retrieved from https://doi.org/10.5465/AMBPP.2017.13866abstra ct

Hu, L., \& Bentler, P. (1999). Cutoff criteria for fit indices in covariance structure analysis: Conventional criteria versus new alternatives. Structural Equation Modeling, 6, 1-55.

Idler, E. L., \& Benyamini, Y. (1997). Self-rated health and mortality: A review of twenty-seven community studies. Journal of Health and Social Behavior, 38(1), 21-37.

Janik, M., \& Rothmann, S. (2015). Meaningful work and secondary school teachers' intention to leave. South African Journal of Education, 35(2), 116129.

Jett, Q., R., \& George, J. M. (2003). Work interrupted: A closer look at the role of interruptions in organizational life. Academy of Management Review, 28(3), 494-507.
Johnson, M. J., \& Jiang, L. (2017). Reaping the benefits of meaningful work: The mediating versus moderating role of work engagement. Stress \& Health, 33(3), 288-297.

Jylhä, M. (2009). What is self-rated health and why does it predict mortality? Towards a unified conceptual model. Social Science \& Medicine, 69(3), 307-316.

Kieschke, U., \& Schaarschmidt, U. (2008). Commitment and health among teachers in Germany: A typological approach. Learning and Instruction, 18, 429-437.

Kyriacou, C. (2001) Teacher Stress: Directions for future research. Educational Review, 53(1), 27-35.

Kyriacou, C. (1987) Teacher stress and burnout: An international review. Educational Research, 29(2), 146-152.

Kööts-Ausmees, L., \& Realo, A. (2015). The association between life satisfaction and selfreported health status in Europe. European Journal of Personality, 29, 647-657.

Lavy, S., \& Bocker, S. (2018). A path to teacher happiness? A sense of meaning affects teacherstudent relationships, which affect job satisfaction. Journal of Happiness Studies, 19, 1485-1503.

Lazarus, R. S., DeLongis, A., Folkman, S., \& Gruen, R. (1985). Stress and adaptational outcomes: The problem of confounded measures. American Psychologist, 40, 770-779.

Leinonen, R., Heikkinen, E., \& Jylhä, M. (2001). Predictors of decline in self-assessments of health among older people - a 5-year longitudinal study. Social Science \& Medicine, 52(9), 1329-1341.

Lin, B. C., Kain, J. M., \& Fritz, C. (2013). Don't interrupt me! An examination of the relationship between intrusions at work and employee strain. International Journal of Stress Management, 20(2), 77-94.

Ma, J., \& Peng, Y. (2019). The performance costs of illegitimate tasks: The role of job identity and flexile role orientation. Journal of Vocational Behavior, 110, 144-154.

Manderbacka, K (1998). Examining what self-rated health question is understood to mean by respondents. Scandinavian Journal of Social Medicine, 26(2), 145-153.

Marsh, H., Hau, K., \& Wen, Z. (2004). In search of golden rules: Comment on hypothesis-testing approaches to setting cutoff values for fit indexes and dangers in overgeneralizing $\mathrm{Hu}$ and Bentler's (1999) findings. Structural Equation Modeling: A Multidisciplinary Journal, 11, 320-341. 
Maslowsky, J., Jager, J., \& Hemken, D. (2015). Estimating and interpreting latent variable interactions: A tutorial for applying the latent moderated structural equations method. International Journal of Behavioral Development, 39(1), 87-96.

Muthén, L.K., \& Muthén, B.O. (1998-2017). Mplus User's Guide. Eighth Edition. Los Angeles, CA: Muthén \& Muthén.

Nelson D. L., \& Simmons B. L. (2003). Health psychology and work stress: A more positive approach. In: J. C. Quick \& L. E. Tetrick (Eds.), Handbook of occupational health psychology (pp. 97-119). Washington, DC: American Psychological Association.

Nixon, A. E., Mazzola, J. J., Bauer, J., Krueger, J. R., Spector, P. E. (2011). Can work make you sick? A meta-analysis of the relationships between job stressors and physical symptoms. Work \& Stress, $25(1), 1-22$.

OAJ (2015). Jäsenen opas [A guide for members of the Trade Union of Education (OAJ)], 5/2015. Retrieved from https://peda.net/yhdistykset/aol/oaj-nmateriaalia/oaj-n-j\%C3\%A4senenopas:file/download/db199863cec10d3dea818eb0e 85bfd62307c024c/Jasenen_opas.pdf

OECD (2014). TALIS 2013 results: An international perspective on teaching and learning. TALIS, OECD Publishing.

Peugh, L. (2010). A practical guide to multilevel modeling. Journal of School Psychology, 48, 85112.

Petrou, P., Demerouti, E., Peeters, M. C., Schaufeli, W. B., \& Hetland, J. (2012). Crafting a job on a daily basis: Contextual correlates and the link to work engagement. Journal of Organizational Behavior, 33(8), 1120-1141.

Richards, J. (2012). Teacher stress and coping strategies: A national snapshot. The Educational Forum, 76, 299-316.

Rosso, B. D., Dekas, K. H., \& Wrzesniewski, A. (2010). On the meaning of work: A theoretical integration and review. Research in Organizational Behavior, 30, 91-127.

Scheuch, K., Haufe, E., \& Seibt, R. (2015). Teachers' health. Deutsches Ärzteblatt International, 112, 347-356.
Schweizer, K., \& Döbrich, P. (2003). Self-reported health, appraisal, coping, and stress in teachers. Psychology Science, 45(1), 92-105.

Semmer, N. K., Tschan, F., Meier, L. L., Facchin, S., \& Jacobshagen, N. (2010). Illegitimate tasks and counterproductive work behavior. Applied Psychology, 59, 70-96.

Semmer, N. K., Jacobshagen, N., Meier, L. L., Elfering, A., Beehr, T. A., Kälin, W., \& Tschan, F. (2015). Illegitimate tasks as a source of work stress. Work \& Stress, 29(1), 32-56.

Selye, H. (1976) Stress without Distress. In: G. Serban (Ed.), Psychopathology of Human Adaptation (pp. 137-146). Boston, MA: Springer.

Simmons, B. L., \& Nelson, D. L. (2007). Eustress at work: Extending the holistic stress model. In D. L. Nelson \& C. L. Cooper (Eds.), Positive Organizational Behavior (p. 40-54). Thousand Oaks, California: Sage.

Spector, P. E., \& Jex, S. M. (1998). Development of four self-report measures of job stressors and strain: Interpersonal conflict at work scale, organizational constraints scale, quantitative workload inventory, and physical symptoms inventory. Journal of Occupational Health Psychology, 3(4), 356-367.

Steger, M. F., Dik, B. J., \& Duffy, R. D. (2012). Measuring meaningful work: The Work and Meaning Inventory (WAMI). Journal of Career Assessment, 20(3), 322-337.

Tims, M., Bakker, A. B., \& Derks, D. (2013). The impact of job crafting on job demands, job resources, and well-being. Journal of Occupational Health Psychology, 18, 230-240.

Ugwy, F. O., \& Onyishi, I. E. (2018). Linking perceived organizational frustration to work engagement: The moderating roles of sense of calling and psychological meaningfulness. Journal of Career Assessment, 26(2), 220-239.

Ursin, H., \& Eriksen, H. R. (2004) The cognitive activation theory of stress. Psychoneuroendocrinology, 29(5), 567-695.

Van Wingerden, J., \& Van der Stoep, J. (2017). The role of meaningful work in employees' workrelated and general well-being. International Journal of Human Resource Studies, 7(4), 23-37.

Willey, C. R. (2016). Meaningful teaching: An interpretive phenomenological analysis of how international school teachers experience meaningful work (Doctoral dissertation). Retrieved 
from

https://repository.library.northeastern.edu/files/ne u:cj82pr580/fulltext.pdf

Wu, S., Wang, R., Zhao, Y., Ma, X., Wu, M., Yan, X., \& He, J. (2013). The relationship between selfrated health and objective health status: A population-based study. BMC public health, 13, 320.

Zajacova, A., \& Dowd, J. B. (2011). Reliability of selfrated health in US adults. American Journal of Epidemiology, 174(8), 977-983. 